\title{
Ventilatory support and mechanical properties of the fibrotic lung acting as a "squishy ball"
}

\author{
Alessandro Marchioni ${ }^{1}$, Roberto Tonelli ${ }^{1,5}$, Giulio Rossi ${ }^{2}$, Paolo Spagnolo ${ }^{3}$, Fabrizio Luppi ${ }^{4}$, Stefania Cerri ${ }^{1}$, \\ Elisabetta Cocconcelli ${ }^{3}$, Maria Rosaria Pellegrino ${ }^{1}$, Riccardo Fantini ${ }^{1}$, Luca Tabbì ${ }^{1}$, Ivana Castaniere ${ }^{1,5}$, \\ Lorenzo Ball ${ }^{6,7}$, Manu L. N. G. Malbrain ${ }^{8,9}$, Paolo Pelosi $i^{6,7^{*}}$ and Enrico Clini ${ }^{1}$
}

\begin{abstract}
Protective ventilation is the cornerstone of treatment of patients with the acute respiratory distress syndrome (ARDS); however, no studies have yet established the best ventilatory strategy to adopt when patients with acute exacerbation of interstitial lung disease (AE-ILD) are admitted to the intensive care unit. Due to the severe impairment of the respiratory mechanics, the fibrotic lung is at high risk of developing ventilator-induced lung injury, regardless of the lung fibrosis etiology. The purpose of this review is to analyze the effects of mechanical ventilation in AE-ILD and to increase the knowledge on the characteristics of fibrotic lung during artificial ventilation, introducing the concept of "squishy ball lung". The role of positive end-expiratory pressure is discussed, proposing a "lung resting strategy" as opposed to the "open lung approach". The review also discusses the practical management of AE-ILD patients discussing illustrative clinical cases.
\end{abstract}

Keywords: Interstitial lung diseases, Acute respiratory distress syndrome, Respiratory failure, Mechanical ventilation, Ventilator-induced lung injury

\section{Background}

Interstitial lung diseases (ILD) represent a group of heterogeneous clinical conditions of both idiopathic and secondary nature, characterized by the coexistence of various degrees of inflammation and lung fibrosis $[1,2]$. Many patients with ILD can develop an acute exacerbation in the course of the disease (AE-ILD), and often require ICU hospitalization and mechanical ventilation (MV). Idiopathic pulmonary fibrosis (IPF) is the most common and severe form of idiopathic ILD, often worsened by acute exacerbation episodes (AE-IPF). During these dramatic events, the typical usual interstitial pneumonia pattern (UIP) - the radiologic and histologic

\footnotetext{
*Correspondence: ppelosi@hotmail.com

${ }^{6}$ Dipartimento di Scienze Chirurgiche e Diagnostiche Integrate,

Università degli Studi di Genova, Genoa, Italy

Full list of author information is available at the end of the article
}

hallmark of IPF is overlapped with diffuse alveolar damage (DAD), sharing similarities with the acute respiratory distress syndrome (ARDS) [3]. Little is known about the outcome of latter patients receiving MV, and the influence of the extent of lung fibrosis component on ventilator management [4].

The purposes of this viewpoint paper are: (1) to describe the mechanical characteristics of the fibrotic lung during MV, introducing the concept of "squishy ball lung" and (2) to discuss the impact of MV in ICU patients with acute exacerbations of ILD.

\section{Specific pathophysiology}

Independent of the underlying condition, the fibrotic lung has particular structural, biochemical and anatomical alterations resulting in profound changes in the mechanics of breathing.

\section{Springer Open}

(c) The Author(s) 2020. This article is licensed under a Creative Commons Attribution 4.0 International License, which permits use, sharing, adaptation, distribution and reproduction in any medium or format, as long as you give appropriate credit to the original author(s) and the source, provide a link to the Creative Commons licence, and indicate if changes were made. The images or other third party material in this article are included in the article's Creative Commons licence, unless indicated otherwise in a credit line to the material. If material is not included in the article's Creative Commons licence and your intended use is not permitted by statutory regulation or exceeds the permitted use, you will need to obtain permission directly from the copyright holder. To view a copy of this licence, visit http://creativecommons.org/licenses/by/4.0/ 


\section{The extracellular matrix in the fibrotic lung}

The extracellular matrix (ECM) consists of a complex network of protein structures (collagen, fibronectin, elastin, glycoproteins and proteoglycans), which play a crucial role in determining the mechanical stability and elastic recoil of the lung. The ECM is a dynamic structure, constantly remodeled by enzymatic processes. In the fibrotic lung, there is a dysregulation of this remodeling process, with imbalance between protein secretion and degradation, with an increase in the deposition of collagen, elastin, proteoglycans and fibronectin [5]. Considering that the main stress-bearing constituents of lung tissue are collagen and elastin fibers, their quantitative and architectural modification can influence the elastic recoil of the lung. Elastin and collagen differ significantly in their mechanical properties. In fact, elastin is responsible for elasticity, especially at low stress levels, and can be stretched by more than $250 \%$ of its original length before breaking, while collagen is more rigid and significantly less stretchable being extendable only by $1-2 \%$ compared to the initial length [6]. Collagen fibers, which in the resting position are folded, are stretched only at high pulmonary volumes, close to the total lung capacity, and act as a blocking system determining the limitation of distention of the lung, and the origin of the curvilinear stress-strain relationship [7, 8] (Fig. 1). Therefore, elastin fibers are the main determinants of the maximum pulmonary volume that can be reached during inflation, beyond which there is a risk of barotrauma and volutrauma due to the breakdown of collagen fibers. This concept can be applied not only to the entire lung, but also to the different lung regions that have their maximum total regional capacity [7]. This is particularly relevant in the fibrotic lung, where the composition of the ECM has a high regional heterogeneity. In IPF, collagen fibers accumulate around myofibroblasts in fibroblastic foci, stiffening the corresponding regions [9].

\section{Histopathological characteristics of the fibrotic lung}

Several histopathological patterns can characterize the lung during AE-ILD; among these, the most severe and common manifestation is the coexistence of DAD overlapped to a UIP pattern. The histopathological hallmarks of the UIP pattern are spatial heterogeneity, temporal heterogeneity with fibroblastic foci and micro-honeycombing. Spatial heterogeneity is defined as the presence of areas of normal tissue interposed to areas with fibrotic alterations. Temporal heterogeneity is the concomitant presence of areas with only slight modifications of the ECM structure and proliferative fibroblast and myofibroblasts aggregates, adjacent to areas of intense fibrosis composed of dense acellular collagen, indicating different

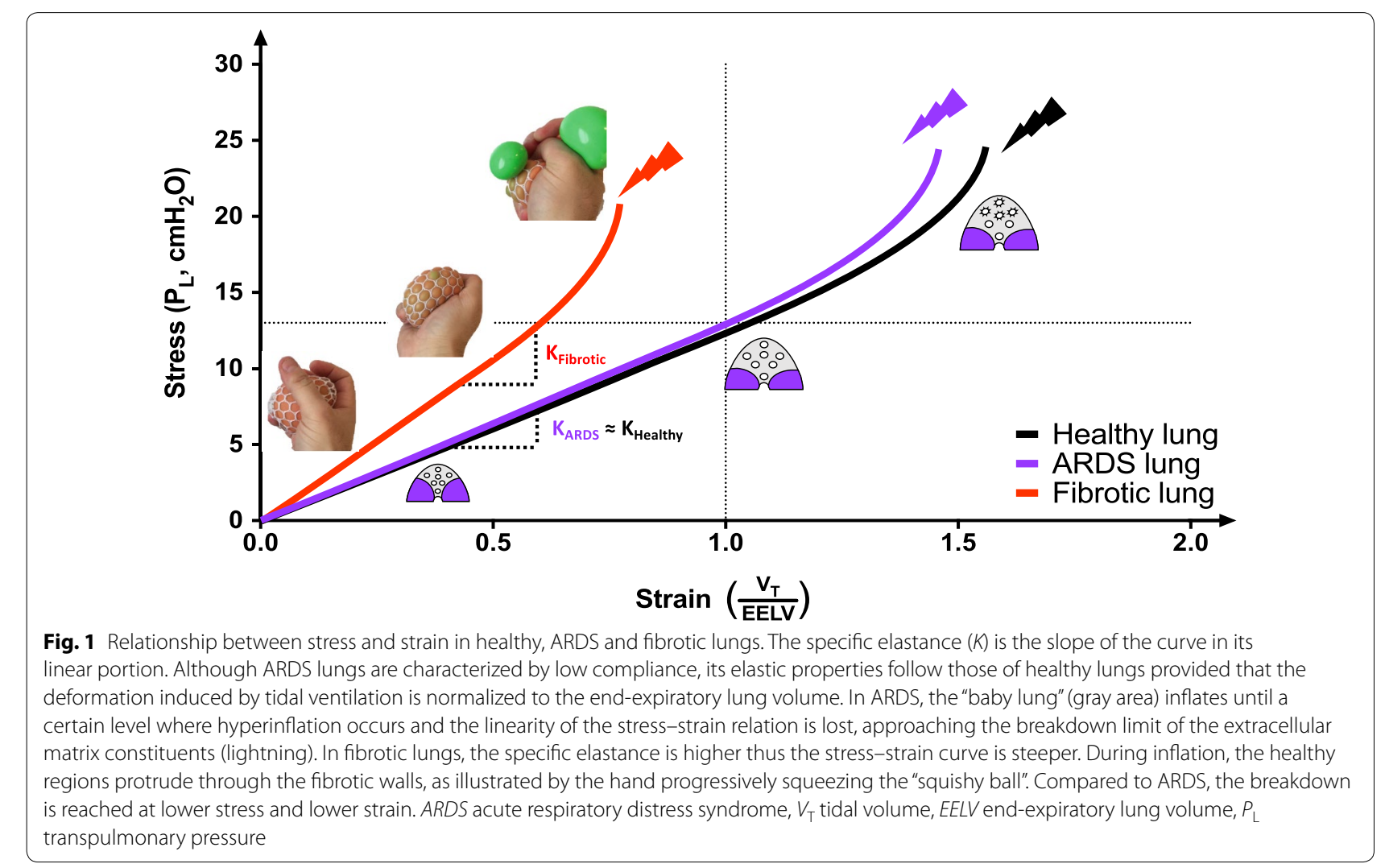


coexisting stages of the disease. Honeycomb lesions are areas consisting of dilated air spaces with anelastic walls of epithelium-coated fibrous tissue [10]. Given these premises, it is clear how the mechanical properties of the fibrotic lung must reflect this histological heterogeneity.

\section{Mechanical properties of the fibrotic lung}

The lung is commonly modeled as an elastic body characterized by minor distortions during inflation. In the nonfibrotic lung, the properties of the parenchyma can be described using two independent elastic modules, which are a function of the transpulmonary pressure $\left(P_{\mathrm{L}}\right)$. The bulk modulus describes the lung behavior during uniform expansion, while the shear modulus $(G)$ describes the non-uniform distortion behavior [11]. The shear modulus modifies approximately linearly as a function of transpulmonary pressure according to the following equation:

$$
G=\alpha \cdot P_{\mathrm{L}}
$$

where $\alpha$ represents the constant of proportionality that is variable according to mammal species.

The relationship between stress and strain is determined by the relationship:

$$
\text { Stress }=Y \cdot \text { Strain, }
$$

where the proportionality constant $Y$ is the Young's modulus. Stress is the equal and opposite force that develops in an elastic material when an external force is applied, namely the transpulmonary pressure $\left(P_{\mathrm{L}}\right)$, while strain is the resulting deformation compared from the resting position, thus the ratio of the tidal volume $\left(V_{\mathrm{T}}\right)$ to the end-expiratory (resting) lung volume (EELV). Equation 2 can thus be rewritten as follows:

$$
P_{L}=K \cdot \frac{V_{T}}{\mathrm{EELV}}
$$

where $K$ corresponds to the specific elastance (Fig. 1), a coefficient describing the elastic properties of the lung whose value in healthy humans is around $13.5 \mathrm{cmH}_{2} \mathrm{O}$ [12]. It can be interpreted as the $P_{\mathrm{L}}$ resulting in lung volume doubling compared to the EELV. When the $P_{\mathrm{L}}$ results in a lung volume above the total lung capacity, stretching of the collagen fibers occurs, causing VILI. Therefore, stress and strain are major determinants of VILI, respectively, involved in barotrauma and volutrauma.

This simple model is not applicable in presence of severe distortion of the pulmonary parenchyma, where $P_{\mathrm{L}}$ is no longer a function of linear elasticity modules, such as occurs in the fibrotic lung where anatomical inhomogeneities result in an anisotropic behavior: the application of $P_{\mathrm{L}}$ in a lung with a patchwork of mechanical-elastic properties has unpredictable consequences on the stress-strain coupling of the various areas of the lung, with high parenchymal distortion during insufflation and consequent increased risk of VILI. In fibrotic lungs, the high retraction forces due to the increased parenchymal rigidity might translate into reduced overall strain. Nevertheless, given the parenchymal heterogeneity, the lung zones without fibrosis might be subjected to intense deformation. In fact, in presence of relevant inhomogeneities the macroscopic lung mechanics parameters do not necessarily reflect what happens at the microscale, where inhomogeneities act as local stress raisers and increase the local $P_{\mathrm{L}}[13]$.

\section{The squishy ball lung theory}

In fibrotic lungs, the effect of PEEP can determine the protrusion of the most distensible lung areas through dense anelastic fibrotic tissue circles, causing increased rigidity and facilitating tissue breakdown. The effect that is determined in some areas of the lung is similar to that shown in stress balls called 'squishy balls' (Figs. 1 and 2). When the squishy ball is compressed, the increase of the pressure inside the object causes throttling of the elastic part of the body through the inelastic net that wraps the ball. The result is the formation of vesicles that protrude outside the net mesh, until reaching the elastic limit. The "squishy ball effect" in some areas of the lung may be the cause of mechanical disadvantages achieved using high $\mathrm{P}_{\text {airway }}$ and $P_{\mathrm{L}}$ in the lungs with fibrosis and could confirm the role of static strain in generating VILI. Moreover, when the most recruitable areas are subject to high $P_{\mathrm{L}}$, the subsequent overinflation is exacerbated by the mechanical geometry of the fibrotic lung as the anelastic areas act as stress raisers.

\section{Clinical implications}

The mentioned pathophysiological and histological characteristics of AE-ILD have implications for the application of MV, titration of PEEP and respiratory monitoring.

\section{Mechanical ventilation and clinical outcome in patients with AE-ILD}

Low tidal volume protective MV is widely recognized as the cornerstone in the treatment of ARDS patients, while in patients with AE-ILD admitted to the ICU, studies have not established yet the best ventilatory strategy. As illustrated above, patients receiving MV for AE-IPF have severe alterations in respiratory mechanics with an increase in the elastance of the respiratory system, mainly due to an abnormal lung elastance while chest wall elastance may be normal (Table 1) [14]. Based on the concepts derived from physiologic studies, experts recommend keeping the static $P_{\mathrm{L}}$ at end-inspiration below $15-20 \mathrm{cmH}_{2} \mathrm{O}$ in homogeneous and below 10-12 

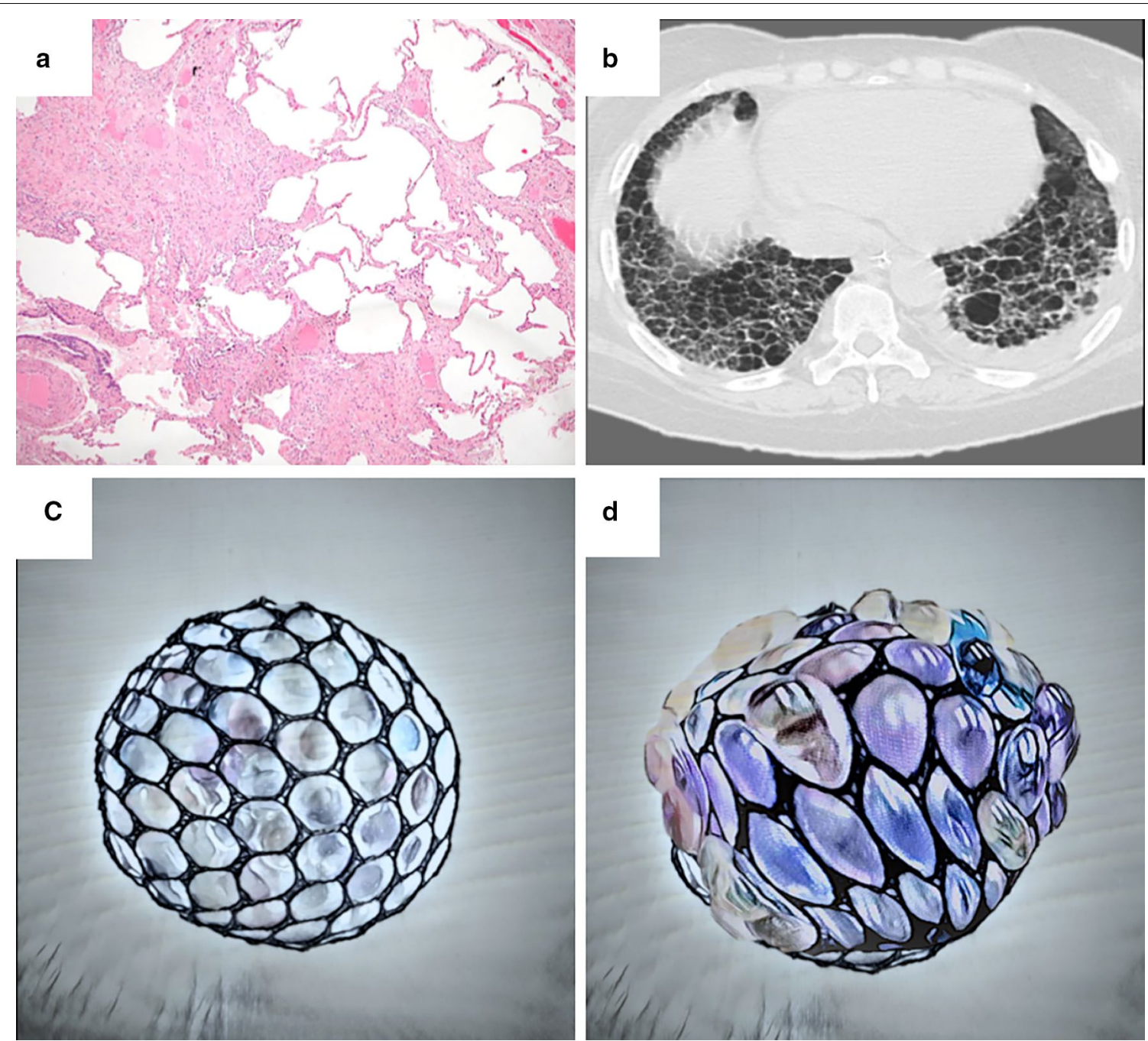

Fig. 2 a Histological evidence of spatial heterogeneity with relatively spared alveolar spaces surrounded by patchy areas of fibrosis with multiple fibroblastic foci in a patient with IPF. b CT appearance of UIP pattern in a patient with IPF. c Graphical appearance of a "squishy ball" depicting the elastic features of fibrotic lung in resting position. $\mathbf{d}$ Squishy ball subjected to the application of an internal pressure: the increase of the pressure inside the object causes throttling of the elastic part of the body through the inelastic net that wraps the ball determining a mechanical disadvantage during the expansion

$\mathrm{cmH}_{2} \mathrm{O}$ in inhomogeneous lung parenchyma, such as in ARDS.

While several studies show that in IPF patients the need for MV is associated with high mortality, little is known about the prognostic impact of MV in ILD other than IPF $[15,16]$. In a recent cohort study in patients with ILD of different etiology hospitalized for acute respiratory failure, survival at 60 months was comparable in IPF and non-IPF patients and ICU admission and the use of MV were the only independent predictors of in-hospital death [17]. Nonetheless, when patients with AE-ILD of different etiology receive MV, the presence of pulmonary hypertension and the evidence of diffuse fibrosis on
CT scan are associated with worse prognosis, while the radiologic extension of lung fibrosis is directly correlated with worse respiratory mechanics and increased mortality [18].

Interestingly, in a case series of mechanically ventilated patients with interstitial pneumonia with autoimmune features, mortality was lower compared to patients with ARDS of known cause [19]. These data may sound surprising but can be linked to the peculiar radiological patterns reported in the series as none of the patients presented a UIP pattern on CT scan, while signs of inflammatory alveolar disease and ground-glass opacities were predominant. These observations suggest that 
Table 1 Lung mechanical properties of three patients experiencing acute exacerbation of interstitial lung disease (AE-ILD)

\begin{tabular}{|c|c|c|c|c|c|c|}
\hline \multirow{2}{*}{$\begin{array}{l}\text { Measurement } \\
\text { PEEP titration strategy }\end{array}$} & \multicolumn{2}{|c|}{ Patient 1 (CHP) } & \multicolumn{2}{|l|}{ Patient 2 (IPF) } & \multicolumn{2}{|c|}{ Patient 3 (CHP) } \\
\hline & $\begin{array}{l}\text { Lung resting } \\
\text { strategy }\end{array}$ & $\begin{array}{l}\text { Open lung } \\
\text { approach }\end{array}$ & $\begin{array}{l}\text { Lung resting } \\
\text { strategy }\end{array}$ & $\begin{array}{l}\text { Open lung } \\
\text { approach }\end{array}$ & $\begin{array}{l}\text { Lung resting } \\
\text { strategy }\end{array}$ & $\begin{array}{l}\text { Open } \\
\text { lung } \\
\text { approach }\end{array}$ \\
\hline Set PEEP $\left(\mathrm{cmH}_{2} \mathrm{O}\right)$ & 4 & 12 & 4 & 12 & 4 & 12 \\
\hline Driving pressure $\left(\mathrm{cmH}_{2} \mathrm{O}\right)$ & 17.0 & 18.0 & 14.5 & 18.0 & 12.0 & 16.0 \\
\hline \multicolumn{7}{|l|}{ Transpulmonary pressure $\left(\mathrm{cmH}_{2} \mathrm{O}\right)$} \\
\hline End-inspiratory & 14.0 & 16.7 & 9.9 & 16.0 & 10.0 & 13.9 \\
\hline End-expiratory & -2.2 & 0.2 & -4.0 & 0.3 & -1.0 & 1.6 \\
\hline Driving pressure & 16.2 & 16.5 & 14.0 & 16.3 & 11.0 & 12.3 \\
\hline \multicolumn{7}{|l|}{ Elastance $\left(\mathrm{cmH}_{2} \mathrm{O} / \mathrm{L}\right)$} \\
\hline Respiratory system & 44.6 & 51.6 & 34 & 47 & 40 & 43 \\
\hline Pulmonary & 42.5 & 47.0 & 33.0 & 45.0 & 35.0 & 37.9 \\
\hline Chest wall & 2.1 & 4.6 & 1.0 & 2.0 & 5.0 & 5.8 \\
\hline Blood arterial $\mathrm{PaO}_{2} / \mathrm{FiO}_{2}(\mathrm{mmHg})$ & 92 & 78 & 113 & 110 & 85 & 79 \\
\hline
\end{tabular}

Patient 1 and 3 presented chronic hypersensitivity pneumonitis (CHF) while patient 2 presented idiopathic pulmonary fibrosis (IPF) In each patient, two PEEP setting strategies were tested: a "lung resting strategy" aimed at minimizing PEEP while maintaining sufficient oxygenation $\left(\mathrm{SpO}_{2}>88-92 \%\right)$ and an "open lung approach" titrating PEEP aiming at avoiding negative end-expiratory transpulmonary pressure. The negative end-expiratory transpulmonary pressure values achieved at $4 \mathrm{cmH}_{2} \mathrm{O}$ PEEP suggest that low levels of PEEP do not prevent tidal alveolar de-recruitment. Nevertheless, higher levels of PEEP determined mild-to-critical increase in lung elastance and non-clinically relevant worsening of gas exchange

PEEP positive end-expiratory pressure

the prognosis of patient with ILD in MV is related to the extension of the lung fibrosis and the presence a UIP pattern on CT scan rather than to the ILD etiology.

\section{Effects of PEEP in AE-ILD}

In ARDS, lung protection is provided using low tidal volumes, low plateau transpulmonary and driving pressures, but also a positive end-expiratory pressure (PEEP) level sufficient to maintain oxygenation while preventing the opening-closing of alveolar units causing shear stress throughout the respiratory cycle [20]. Clinical trials in ARDS investigated the effect of an open lung strategy, namely involving the use of PEEP levels higher than those strictly required to maintain acceptable oxygenation [21], often in conjunction with recruitment maneuvers to maximize lung aeration [22]. Such studies have not been able to show clear advantages in terms of outcome compared to ventilation with lower PEEP levels. Furthermore, an aggressive recruitment strategy used in one study resulted even in increased mortality [23]. Some authors started to suggest that lung pressures, including PEEP, should be minimized to reduce VILI in patients with injured and non-injured lungs [24-26]; these concepts seem to be promising also for fibrotic lungs where susceptibility to VILI is particularly high.

Interestingly, in the patients with fibrotic lung and superimposed DAD, retrospective data showed an association between higher PEEP levels and mortality [16]. Compared to ARDS, physiology of MV in IPF patients is much less known [3], and it is unclear whether opening and closing of alveolar units during tidal breathing occurs, as what exactly the role of PEEP is on alveolar recruitment.

Monitoring $P_{\mathrm{L}}$ through esophageal pressure assessment [27] has been proposed to identify patients with regional alveolar collapse at the end of expiration, suggested by a negative end-expiratory $P_{\mathrm{L}}$. Physiologic studies confirmed that $P_{\mathrm{L}}$ estimated by esophageal manometry reflects the regional $P_{\mathrm{L}}$ of dependent lung areas where atelectasis predominate $[28,29]$. Titrating PEEP to target a positive $P_{\mathrm{L}}$ at end-expiration maximizes lung recruitment and improves respiratory mechanics and oxygenation in ARDS [30], but did not improve survival in ARDS when compared to empirical high PEEP [31]. This particular technique is one of the methods proposed to achieve an "open lung approach". However, despite decades of intense clinical research in ARDS, ventilatory strategies aimed at achieving an 'open lung' (open the lung and keep it open) with the use of PEEP failed to translate these findings in the clinical setting [32], and some author suggested the 'lung rest' (close the lung and keep it resting) strategy [24].

Despite the lack of physiological data in AE-ILD patients, it might be assumed that expiratory derecruitment occurs in parenchymal areas spared from fibrosis with preserved elasticity. Despite a possible role of incremental PEEP in the recruitment of these areas, the reported association between higher PEEP levels and 
mortality in AE-ILD [16], indicates a critical role of static strain in determining VILI in patients with fibrotic lungs, and might suggest that limiting airway pressures, including PEEP, could be preferable.

\section{Practical management tips}

This paragraph illustrates practical aspects of the clinical management of patients with AE-ILD.

\section{Clinical pathway of patients with AE-ILD}

Overall, AE-ILD has a poor prognosis and the choice to initiate MV or to admit the patient to the ICU can be challenging, particularly in patients with IPF [3]. In several clinical settings, ICU physicians tend to be reluctant to admit IPF patients if they are not already listed for transplant, considering invasive ventilation as a bridge-totransplant therapy [16]. Nevertheless, evidence shows that also patients with ILD other than IPF may present with acute exacerbation during the natural course of the disease [33] requiring ICU admission and MV [15, 33, 34]. Autopsy studies show that the majority of patients who died from AE-ILD other than IPF often present with a DAD superimposed on a UIP pattern at the histologic examination, resembling what usually is found on biopsies of patients that died from AE-IPF [34, 35]. The presence of a UIP pattern on histology is strictly correlated with peculiar features on $\mathrm{CT}$ scan, namely radiological UIP pattern [33]. Therefore, intensivists should be able to promptly recognize the UIP pattern at the CT scan, as it is the main determinant of the squishy-ball behavior of the fibrotic lung subject to MV.

\section{How to identify the AE-ILD radiological pattern}

The correct identification of UIP pattern at the CT scan can be useful in the clinical evaluation of patients with AE-ILD whose lung mechanical substrate is more prone to the development of VILI once subjected to MV with worst clinical outcomes. The ultimate guidelines on diagnosis of IPF defined the typical radiographic features of UIP pattern on CT. The radiologic hallmark of UIP is the presence of honeycombing, multiple layers of subpleural clustered cystic airspaces with thick, well-defined walls and typically consistent diameter $(3-10 \mathrm{~mm}$, but occasionally larger). A fine reticular pattern containing traction bronchiectasis ranging from subtle irregularity of the bronchial/bronchiolar wall to marked airway distortion and varicosity is another key feature of UIP pattern. The typical distribution of these abnormalities follows a cranio-caudal gradient with sub-pleural predominance [36]. Ground-glass opacifications as defined by hazy increased opacity of lung airspaces with substantial preservation of the bronchial and vascular margins on $\mathrm{CT}$, represent the usual radiological appearance of inflammatory alveolar abnormalities, including DAD [37] but may be also present in patients with ILD [38]. When ground-glass opacifications result superimposed on a fine reticular pattern surrounded by traction bronchiectasis they should be referred to alveolar fibrosis and might identify a subgroup of patients at extremely high risk of VILI [39]. In summary, in the context of ILD of different etiology, the presence of a UIP pattern identifies a mechanical substrate more prone to VILI as a consequence of the "squishy ball" behavior. In this setting a lung resting approach might be preferable to prevent possible damages. In AE-ILD patients with ground-glass abnormalities in the absence of significant UIP pattern, mechanical behavior of the lung might be similar to ARDS.

\section{How to set mechanical ventilation}

There is lack of specific evidence concerning MV settings in AE-ILD. Some of the recommendations can be derived from the evidence concerning ARDS, but several other aspects need to be elucidated in further research [3]. Advanced respiratory monitoring, including esophageal pressure where available, is important to identify those patients more prone to VILI [40].

Concerning tidal volume, we recommend targeting $6 \mathrm{ml} / \mathrm{kg}$ of predicted body weight, as established in ARDS [41]. In case of high driving and/or plateau pressures a further reduction could be considered [42], however this strategy in AE-ILD can lead to unacceptable hypercapnia. The respiratory rate should be set to avoid respiratory acidosis, tolerating hypercapnia if the arterial $\mathrm{pH}$ remains above 7.25. Attention should be paid to the presence of intrinsic PEEP, namely a careful inspection of the flowtime curve should be performed to ensure that the expiratory flow reaches zero at end-expiration.

The use of high PEEP levels does not seem appropriate, due to the peculiar characteristics of the fibrotic lung. We advocate the adoption of a "lung resting strategy", tolerating moderate atelectasis titrating PEEP to the minimal values necessary to achieve minimal oxygenation, i.e., an arterial partial pressure of oxygen above $50-60 \mathrm{mmHg}$ or a $\mathrm{SpO}_{2}$ above $88-90 \%$. In patients in whom a DAD or ground-glass opacities at the CT predominate over the UIP pattern, higher PEEP levels might be considered, similarly to ARDS.

\section{Illustrative cases}

We assessed retrospectively clinical data of three patients with AE-ILD of different etiology admitted to the Respiratory Intensive Care Unit of the University Hospital of Modena, Italy, from January 2016 to January 2018 to receive invasive controlled MV: one had IPF and two had chronic hypersensitivity pneumonitis (CHP). All patients 
presented a UIP pattern with superimposed ground-glass opacities on the CT scan (Fig. 3a). Patients were nonobese males (body mass index, mean \pm standard deviation of $22.8 \pm 2.3 \mathrm{~kg} / \mathrm{m}^{2}$ ), aged $62.6 \pm 9.1$ (age at diagnosis $60 \pm 8.5$ years). All patients underwent transpulmonary pressure monitoring with esophageal manometry (Fig. 3b). Table 1 shows respiratory mechanics and gas exchange parameters of these patients, when PEEP was set according to a "lung resting strategy" (minimal PEEP level of $4 \mathrm{cmH}_{2} \mathrm{O}$ ) and after PEEP titration on an "open lung approach" aiming at achieving positive end-expiratory transpulmonary pressure values. In all patients, with minimal levels of PEEP aimed at achieving minimal acceptable oxygenation, end-expiratory $P_{\mathrm{L}}$ was negative. This suggests that even in the fibrotic lung with diffuse alveolar damage tidal de-recruitment of the dependent zones during the expiration might occur. Nevertheless, in these patients a PEEP titration strategy to maintain a positive end-expiratory $P_{\mathrm{L}}$ resulted in a significant mechanical disadvantage. In these patients, higher PEEP levels lead to an increase in the driving pressure, lung elastance and end-inspiration $P_{\mathrm{L}}$ values. This suggest that PEEP is able to counteract alveolar recruitment-derecruitment, but at the price of a remarkable lung parenchymal stress. The mechanical disadvantages determined by high PEEP, suggests that in the fibrotic lung with diffuse alveolar damage, the static strain might play a relevant role.

\section{Conclusions}

The management of the patient with lung fibrosis in the ICU is a challenge for the intensivist. The lack of studies defining the mechanical ventilation strategy, and the different underlying etiologies, make it difficult to decide which patient can benefit from ICU admission and MV. The few data that are available show that the prognosis of patients with non-IPF pulmonary fibrosis subjected to MV is dependent on the degree of extensive fibrosis present on CT scan, rather than the underlying etiology. The architecture of the fibrotic lung makes it particularly fragile when subjected to high PEEP. The presence of conserved lung areas, next to areas of dense anelastic fibrosis, does not prevent the

\section{a}

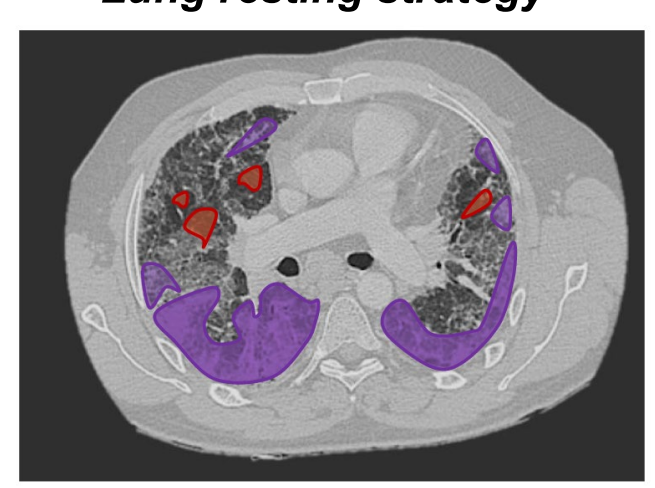

b

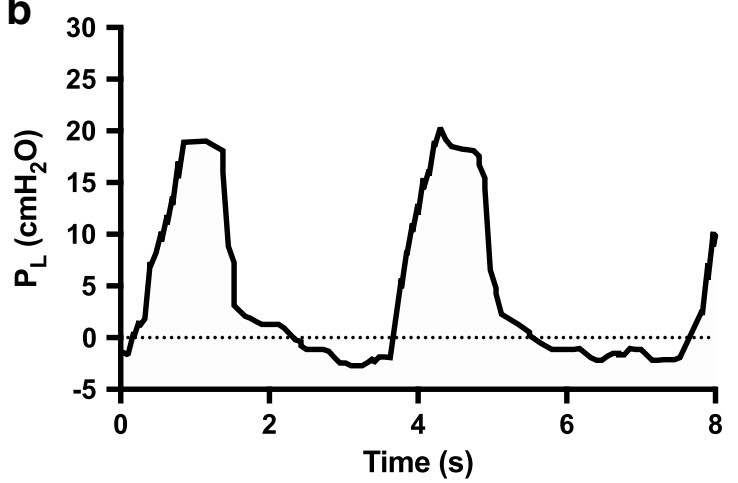

Open lung approach
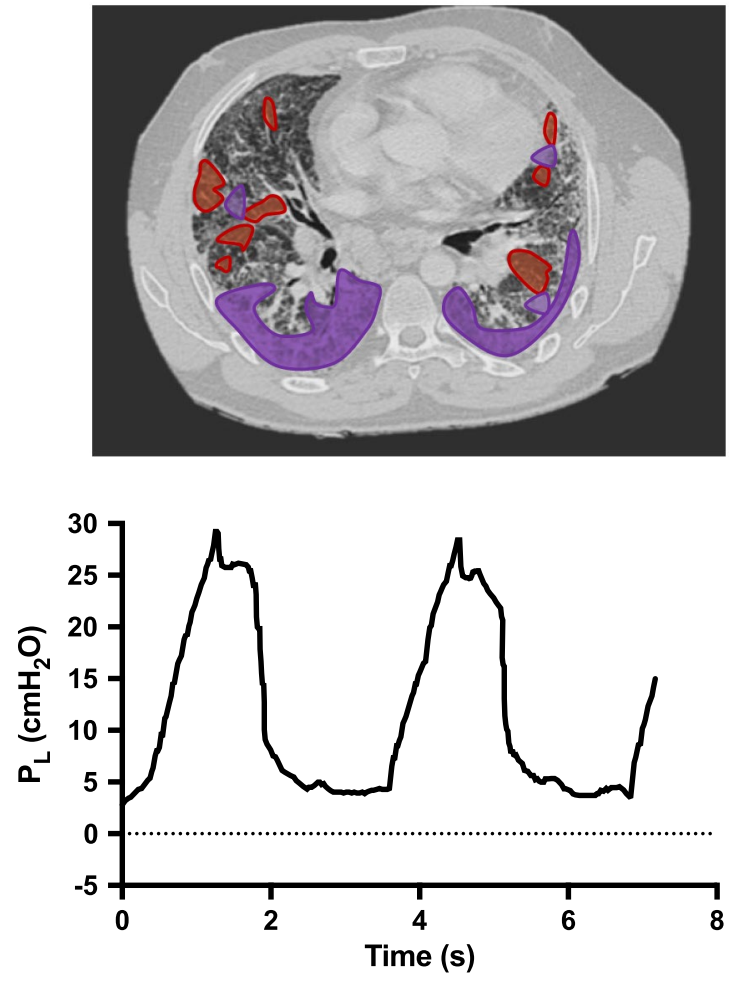

Fig. 3 CT scan images and transpulmonary pressure monitoring of a representative patient with UIP pattern and superimposed ground-glass during an AE-ILD, with PEEP set according to a "lung resting strategy" (left, PEEP $4 \mathrm{cmH}_{2} \mathrm{O}$ ) or with an "open lung approach" titrated to achieve positive end-expiratory transpulmonary pressure (right, PEEP $12 \mathrm{cmH}_{2} \mathrm{O}$ ). End-inspiratory transpulmonary pressure values significantly rise when higher values of PEEP are applied. Purple areas represent lung collapse, opacities and fibrous regions. Red circles highlight areas of over-inflation. AE acute exacerbation, ILD interstitial lung disease, UIP usual interstitial pneumonia, PEEP positive end-expiratory pressure 
phenomenon of alveolar recruitment-derecruitment during tidal volume. The use of high PEEP to keep alveolar units opened during expiration exposes the lung at risk of injury by forming "squishy ball" lung areas that aggravate the end-inspiratory transpulmonary pressure effects. Pending further studies to define the optimal strategy to ventilate these lungs, we herein suggest using a "lung resting strategy", as opposed to "open lung approach" in patients affected by pulmonary fibrosis and UIP pattern under MV, regardless of the underlying etiology.

\begin{abstract}
Abbreviations
AE: Acute exacerbation; IPF: Idiopathic pulmonary fibrosis; ILD: Interstitial lung diseases; UIP: Usual interstitial pneumonia; DAD: Diffuse alveolar damage; EELV: End-expiratory lung volume; ICU: Intensive Care Unit; PEEP: Positive endexpiratory pressure; MV: Mechanical ventilation; $V_{T}$ : Tidal volume; ARDS: Acute respiratory distress syndrome; VILI: Ventilator-induced lung injury; ARF: Acute respiratory failure; CHP: Chronic hypersensitivity pneumonitis; CT: Computed tomography; ECM: Extracellular matrix.
\end{abstract}

\section{Acknowledgements}

None.

\section{Authors' contributions}

AM, RT and LB have made substantial contributions to conception of the paper. GR, PS, FL and SC reviewed the literature and wrote the manuscript. DC, IC, RF, MRP, LB and LT wrote the manuscript and produced the figures. EC, MLNGM and PP reviewed and edited the manuscript. All authors read and approved the final manuscript.

\section{Authors' information}

Dr. Manu Malbrain is professor at the faculty of Medicine and Pharmacy at the Vrije Universiteit Brussels (VUB) and member of the Executive Committee of the Abdominal Compartment Society, formerly known as the World Society of Abdominal Compartment Syndrome (https://www.wsacs.org/). He is cofounder and past president of WSACS and current Treasurer. He is co-founder of the International Fluid Academy (IFA). The IFA is integrated within the notfor-profit charitable organization iMERiT, International Medical Education and Research Initiative, under Belgian law. The content of the IFA website (http:// www.fluidacademy.org) is based on the philosophy of FOAM (Free Open Access Medical education - \#FOAMed).

\section{Funding}

Not applicable.

\section{Availability of data and materials}

Not applicable.

\section{Ethics approval and consent to participate}

Not applicable.

\section{Consent for publication}

Consent for publication was obtained from all patients.

\section{Competing interests}

The authors have no financial involvement with any organization or entity with a financial interest in competition with the subject, matter or materials discussed in the manuscript. MLNGM is a member of the medical advisory Board of Pulsion Medical Systems (now fully integrated in Getinge, Solna, Sweden) and Serenno Medical (Tel Aviv, Israel), consults for Baxter, Maltron, ConvaTec, Acelity, Spiegelberg and Holtech Medical.

\section{Author details}

${ }^{1}$ Respiratory Diseases Unit, Department of Medical and Surgical Sciences, University Hospital of Modena and Center for Rare Lung Diseases, University of Modena Reggio Emilia, Modena, Italy. ${ }^{2}$ Pathologic Anatomy Unit, Azienda USL Ravenna, Ravenna, Rimini, Italy. ${ }^{3}$ Respiratory Diseases Unit, University of Padua, Padua, Italy. ${ }^{4}$ Respiratory Unit, University of Milano Bicocca, S. Gerardo Hospital, Monza, Italy. ${ }^{5}$ Clinical and Experimental Medicine PhD Program, University of Modena Reggio Emilia, Modena, Italy. ${ }^{6}$ Dipartimento di Scienze Chirurgiche e Diagnostiche Integrate, Università degli Studi di Genova, Genoa, Italy. ${ }^{7}$ Ospedale Policlinico San Martino, IRCCS per I'Oncologia e le Neuroscienze, Genoa, Italy. ${ }^{8}$ Intensive Care Unit Department, University Hospital Brussels (UZB), Jette, Belgium. ${ }^{9}$ Faculty of Medicine and Pharmacy, Vrije Universiteit Brussel (VUB), Brussels, Belgium.

Received: 16 June 2019 Accepted: 24 January 2020

Published online: 04 February 2020

\section{References}

1. Travis WD, Costabel U, Hansell DM, King TE, Lynch DA, Nicholson AG, et al. An official American Thoracic Society/European Respiratory Society statement: update of the international multidisciplinary classification of the idiopathic interstitial pneumonias. Am J Respir Crit Care Med. 2013;188:733-48.

2. Fischer A, du Bois R. Interstitial lung disease in connective tissue disorders. Lancet. 2012;380:689-98.

3. Marchioni A, Tonelli R, Ball L, Fantini R, Castaniere I, Cerri S, et al. Acute exacerbation of idiopathic pulmonary fibrosis: lessons learned from acute respiratory distress syndrome? Crit Care. 2018;22:80.

4. Tachikawa R, Tomii K, Ueda H, Nagata K, Nanjo S, Sakurai A, et al. Clinical features and outcome of acute exacerbation of interstitial pneumonia: collagen vascular diseases-related versus idiopathic. Respiration. 2012:83:20-7.

5. Upagupta C, Shimbori C, Alsilmi R, Kolb M. Matrix abnormalities in pulmonary fibrosis. Eur Respir Rev. 2018;27:180033.

6. Faffe DS, Zin WA. Lung parenchymal mechanics in health and disease. Physiol Rev. 2009:89:759-75.

7. Gattinoni L, Pesenti A. The concept of "baby lung". Intensive Care Med. 2005;31:776-84.

8. Gattinoni L, Marini JJ, Pesenti A, Quintel M, Mancebo J, Brochard L. The, "baby lung" became an adult. Intensive Care Med. 2016;42:663-73.

9. Kuhn C, Boldt J, King TE, Crouch E, Vartio T, McDonald JA. An immunohistochemical study of architectural remodeling and connective tissue synthesis in pulmonary fibrosis. Am Rev Respir Dis. 1989;140:1693-703.

10. Plantier L, Cazes A, Dinh-Xuan A-T, Bancal C, Marchand-Adam S, Crestani B. Physiology of the lung in idiopathic pulmonary fibrosis. Eur Respir Rev. 2018;27:170062.

11. Lambert RK, Paré PD. Lung parenchymal shear modulus, airway wall remodeling, and bronchial hyperresponsiveness. J Appl Physiol. 1997;83:140-7.

12. Chiumello D, Carlesso E, Cadringher P, Caironi P, Valenza F, Polli F, et al. Lung stress and strain during mechanical ventilation for acute respiratory distress syndrome. Am J Respir Crit Care Med. 2008;178:346-55.

13. Cressoni M, Cadringher P, Chiurazzi C, Amini M, Gallazzi E, Marino A, et al. Lung inhomogeneity in patients with acute respiratory distress syndrome. Am J Respir Crit Care Med. 2014;189:149-58.

14. Nava S, Rubini F. Lung and chest wall mechanics in ventilated patients with end stage idiopathic pulmonary fibrosis. Thorax. 1999;54(5):390-5.

15. Güngör G, Tatar D, Saltürk C, Çimen P, Karakurt Z, Kirakli C, et al. Why do patients with interstitial lung diseases fail in the ICU? A 2-center cohort study. Respir Care. 2013;58:525-31.

16. Fernández-Pérez ER, Yilmaz M, Jenad H, Daniels CE, Ryu JH, Hubmayr RD, et al. Ventilator settings and outcome of respiratory failure in chronic interstitial lung disease. Chest. 2008;133:1113-9.

17. Moua T, Westerly BD, Dulohery MM, Daniels CE, Ryu JH, Lim KG. Patients with fibrotic interstitial lung disease hospitalized for acute respiratory worsening: a large cohort analysis. Chest. 2016;149:1205-14.

18. Zafrani L, Lemiale V, Lapidus N, Lorillon G, Schlemmer B, Azoulay E. Acute respiratory failure in critically ill patients with interstitial lung disease. PLOS ONE. 2014;9:e104897.

19. Grasselli G, Vergnano B, Pozzi MR, Sala V, D’Andrea G, Scaravilli V, et al. Interstitial pneumonia with autoimmune features: an additional risk factor for ARDS? Ann Intensive Care. 2017;7:98. 
20. Sahetya SK, Goligher EC, Brower RG. Setting positive end-expiratory pressure in acute respiratory distress syndrome. Care Med: Am J Respir Crit; 2017.

21. Kacmarek RM, Villar J, Sulemanji D, Montiel R, Ferrando C, Blanco J, et al. Open lung approach for the acute respiratory distress syndrome: a pilot randomized controlled trial. Crit Care Med. 2016;44:32-42.

22. Fujino Y, Goddon S, Dolhnikoff M, Hess D, Amato MBP, Kacmarek RM Repetitive high-pressure recruitment maneuvers required to maximally recruit lung in a sheep model of acute respiratory distress syndrome. Crit Care Med. 2001;29:1579-86.

23. Cavalcanti AB, Suzumura ÉA, Laranjeira LN, De Moraes Paisani D, Damiani $L P$, Guimarães HP, et al. Effect of lung recruitment and titrated Positive End-Expiratory Pressure (PEEP) vs low PEEP on mortality in patients with acute respiratory distress syndrome - a randomized clinical trial. JAMA. 2017;318:1335-45.

24. Pelosi P, Rocco PR, de Abreu MG. Close down the lungs and keep them resting to minimize ventilator-induced lung injury. Critical Care. 2018;2(1):72.

25. Cruz FF, Ball L, Rocco PRM, Pelosi P. Ventilator-induced lung injury during controlled ventilation in patients with acute respiratory distress syndrome: less is probably better. Expert Rev Respir Med. 2018;12:403-14

26. Pelosi P, Ball L, de Abreu MG, Rocco PR. General anesthesia closes the lungs: keep them resting. Turk J Anaesthesiol Reanim. 2016;44(4):163.

27. Akoumianaki E, Maggiore SM, Valenza F, Bellani G, Jubran A, Loring SH, et al. The application of esophageal pressure measurement in patients with respiratory failure. Am J Respir Crit Care Med. 2014;189:520-31.

28. Yoshida T, Amato MBP, Grieco DL, Chen L, Lima CAS, Roldan R, et al. Esophageal manometry and regional transpulmonary pressure in lung injury. Am J Respir Crit Care Med. 2018;197:1018-26.

29. Mietto C, Malbrain MLNG, Chiumello D. Transpulmonary pressure monitoring during mechanical ventilation: a bench-to-bedside review. Anestezjol Intens Ter. 2015;47:27-37.

30. Talmor D, Sarge T, Malhotra A, O'Donnell CR, Ritz R, Lisbon A, et al. Mechanical ventilation guided by esophageal pressure in acute lung injury. N Engl J Med. 2008;359:2095-104.

31. Beitler JR, Sarge T, Banner-Goodspeed VM, Gong MN, Cook D, Novack $\checkmark$, et al. Effect of titrating positive end-expiratory pressure (PEEP) with an esophageal pressure-guided strategy vs an empirical high $\mathrm{PEEP}-\mathrm{FIO}_{2}$ strategy on death and days free from mechanical ventilation among patients with acute respiratory distress syndrome: a randomized clinical trial. JAMA. 2019;321:846-57.
32. Walkey AJ, Del Sorbo L, Hodgson CL, Adhikari NKJ, Wunsch H, Meade MO, et al. Higher PEEP versus lower PEEP strategies for patients with acute respiratory distress syndrome: a systematic review and meta-analysis. Ann Am Thorac Soc. 2017;14:S297-303.

33. Park IN, Kim DS, Shim TS, Lim CM, Do Lee S, Koh Y, et al. Acute exacerbation of interstitial pneumonia other than idiopathic pulmonary fibrosis. Chest. 2007;132(1):214-20.

34. Miyazaki Y, Tateishi T, Akashi T, Ohtani Y, Inase N, Yoshizawa Y. Clinical predictors and histologic appearance of acute exacerbations in chronic hypersensitivity pneumonitis. Chest. 2008;134:1265-70.

35. Rice AJ, Wells AU, Bouros D, du Bois RM, Hansell DM, Polychronopoulos V, et al. Terminal diffuse alveolar damage in relation to interstitial pneumonias. An autopsy study. Am J Clin Pathol. 2003;119:709-14.

36. Raghu G, Remy-Jardin M, Myers JL, Richeldi L, Ryerson CJ, Lederer DJ, et al Diagnosis of idiopathic pulmonary fibrosis. an official ATS/ERS/JRS/ALAT clinical practice guideline. Am J Respir Crit Care Med. 2018;198:e44-68.

37. Kim DS, Park JH, Park BK, Lee JS, Nicholson AG, Colby T. Acute exacerbation of idiopathic pulmonary fibrosis: frequency and clinical features. Eur Respir J. 2006;27:143-50.

38. Hansell DM, Bankier AA, MacMahon H, McLoud TC, Müller NL, Remy J. Fleischner society: glossary of terms for thoracic imaging. Radiology. 2008;246:697-722.

39. Ryerson CJ, Cottin V, Brown KK, Collard HR. Acute exacerbation of idiopathic pulmonary fibrosis: shifting the paradigm. Eur Respir J. 2015:46:512-20.

40. Ball L, Sutherasan Y, Pelosi P. Monitoring respiration: what the clinician needs to know. Best Pract Res Clin Anaesthesiol. 2013;27:209-23.

41. Brower RG, Matthay MA, Morris A, Schoenfeld D, Thompson BT, et al. Ventilation with lower tidal volumes as compared with traditional tidal volumes for acute lung injury and the acute respiratory distress syndrome network. N Engl J Med. 2000;342:1301-8.

42. Pelosi P, Ball L. Should we titrate ventilation based on driving pressure? Maybe not in the way we would expect. Ann Transl Med. 2018;6:389.

\section{Publisher's Note}

Springer Nature remains neutral with regard to jurisdictional claims in published maps and institutional affiliations.

\section{Submit your manuscript to a SpringerOpen ${ }^{\circ}$ journal and benefit from:}

- Convenient online submission

- Rigorous peer review

- Open access: articles freely available online

- High visibility within the field

- Retaining the copyright to your article

Submit your next manuscript at $\boldsymbol{\nabla}$ springeropen.com 